\title{
Carbon Monoxide Diffusing Capacity in Newborn Infants
}

\author{
ALFRED N. KRAUSS, DAVID B. KLAIN, AND PETER A. M. AULD ${ }^{21}$ \\ Division of Newborn Medicine, Department of Pediatrics, New York Hospital-Cornell University Medical Center, \\ New York, New York, USA
}

\begin{abstract}
Extract
In order to test the role of diffusing capacity in determining the arterial oxygen tension of newborn infants, pulmonary diffusing capacity for carbon monoxide $\left(\mathrm{DL}_{\mathrm{CO}}\right)$ was measured in 21 healthy infants ranging in birth weight from 765 to $4,720 \mathrm{~g}$. $\mathrm{DL}_{\mathrm{CO}}$ in infants without respiratory distress correlated well with lung volume $(r=0.76, P<\mathbf{0 . 0 0 1})$. A smaller correlation $(r=0.39, P<0.01)$ was obtained between $\mathrm{DL}_{\mathrm{CO}}$ and arterial oxygen tension. $\mathrm{DL}_{\mathrm{CO}_{\mathrm{O}}}$ per unit volume of lung is similar when healthy premature infants, full term infants, and normal adults are compared. The wide range of normal values obtained in resting infants and the lack of correlation with arterial oxygen tensions are similar to observations made in adults.
\end{abstract}

\section{Speculation}

Diffusion "block" was not demonstrable in this study, even in infants with mild hypoxemia. These data, in conjunction with other studies reviewed in this report, suggest that lung volume plays a critical role in the level of arterial oxygen tension in newborn infants.

Defects in oxygenation of the low birth weight newborn are well known $(16,17)$. These have been ascribed largely to right-to-left shunts through the foramen ovale and patent ductus arteriosus and intrapulmonary shunting through areas of atelectasis. Two other possible causes for hypoxemia while breathing room air exist. Mismatching of ventilation and perfusion with the creation of areas or relative underventilation has not been shown to be a significant cause of arterial hypoxemia in the healthy neonate after the first day of life (11). Reduced diffusing capacity (alveolarcapillary block) has not yet been studied extensively in the low birth weight infant, although it has been suggested that reduced diffusing capacity may contribute to the hypoxemia noted in infants recovering from hyaline membrane disease $(1,14)$. The present study was undertaken in order to provide standards for diffusing capacity in low birth weight neonates and to apply these standards to a group of infants with hyaline membrane disease during the acute and recovery phases of their respiratory distress.

\section{METHODS}

Patients were selected from the nursery population of the Neonatal Special Care Unit of The New York Hospital. Twentyone healthy infants (cases $1-21$ ) ranging in birth weight from 765 to $4,720 \mathrm{~g}$ were studied on 43 occasions at ages ranging from birth to 55 days of age. None of these infants had either respiratory distress or hemolytic disease of the newborn, as determined by standard clinical, radiologic, and biochemical criteria. All were of appropriate weight for gestational age. Complete data on these infants are presented in Table 1.

In addition, eight infants (cases $A-H$ ) with hyaline membrane disease were studied (Table 2). All showed classical x-ray changes of hyaline membrane disease as well as the usual clinical criteria of tachypnea, cyanosis, and retractions in room air. One infant who died (infant $H$ ) had atelectasis and hyaline membrane formation at autopsy. When studied, these infants were all breathing spontaneously and were tolerant of oxygen concentrations of $40 \%$ oxygen or less.

Each infant underwent a determination of arterial oxygen and carbon dioxide tensions and $\mathrm{pH}$ while breathing either room air ( $21 \%$ oxygen) or $100 \%$ oxygen. Blood was obtained anaerobically from either the temporal or right radial artery in a glass gas-tight syringe. Analyses were performed immediately on an Instrumentation Laboratories IL 123 blood gas system calibrated with gas and blood. End-tidal $\mathrm{CO}_{2}$ was sampled with a rapid response Beckman infrared $\mathrm{CO}_{2}$ meter. Alveolar $\mathrm{CO}_{2}$ was determined from the capnograph tracing and used to calculate alveolar oxygen tension by the alveolar air equation (6). Arterial-alveolar gradients for oxygen and carbon dioxide were calculated. Functional residual capacity (FRC) was determined using a helium rebreathing method (11).

$\mathrm{DL}_{\mathrm{CO}}$ was measured using the steady state method of Filley and colleagues (8). Nondistressed infants were given $0.1 \%$ carbon monoxide in room air. Those with hyaline membrane disease received $0.05 \%$ carbon monoxide in $40 \%$ oxygen. Infants rebreathed the test gas through a tightly fitting rubber-rimmed face mask with one-way valves and minimal (under $2 \mathrm{cc}$ ) dead space. The test gas was stored in a spirometer. By observing the movement of the spirometer in conjunction with the valves in the mask a leak test could be carried out. Expired gas was collected in a gas-tight Neoprene anesthesia bag and immediately analyzed for carbon dioxide tension and for carbon monoxide tension. This apparatus is depicted in Figure 1. Carbon monoxide analyses were carried out with a Beckman infrared analyzer calibrated with gas of known carbon monoxide tensions. Physiologic dead space-tidal volume ratio $\left(\mathrm{V}_{\mathrm{D}} / \mathrm{V}_{\mathrm{T}}\right)$ was calculated using the formula

$$
\mathrm{V}_{\mathrm{D}} / \mathrm{V}_{\mathrm{r}}=\frac{\text { arterial } \mathrm{pCO} \mathrm{C}_{2}-\text { expired } \mathrm{pCO}_{2}}{\text { arterial } \mathrm{pCO}_{2}}
$$

This ratio was used to calculate the alveolar carbon monoxide tension. Minute volume was estimated from the spirometer. Minute uptake of carbon monoxide $\left(\dot{\mathrm{V}}_{\mathrm{Co}}\right)$ was determined from the differences in inspired and expired carbon monoxide tensions. $\mathrm{DL}_{\mathrm{co}}$ was then calculated and expressed as cubic centimeters of $\mathrm{CO}$ uptake per min per $\mathrm{mm} \mathrm{Hg}$ of $\mathrm{pACO}_{2}$. For purposes of comparison between infants, $\mathrm{DL}_{\mathrm{CO}}$ is expressed alone, per cc FRC, per $\mathrm{kg}$ body weight, and per $\mathrm{m}^{2}$ body surface area.

Patients were allowed to breathe the test gas for 2-3 min before the collection of expired gas began. This was to enable their lungs to be completely washed out with the test gas. Expired gas was collected for 2 min. All infants were studied after a meal and at thermoneutral temperature. Those with respiratory distress were studied while in their Isolettes. The test was abandoned for crying or restlessness. Initially infants were rechecked within $6 \mathrm{hr}$. 


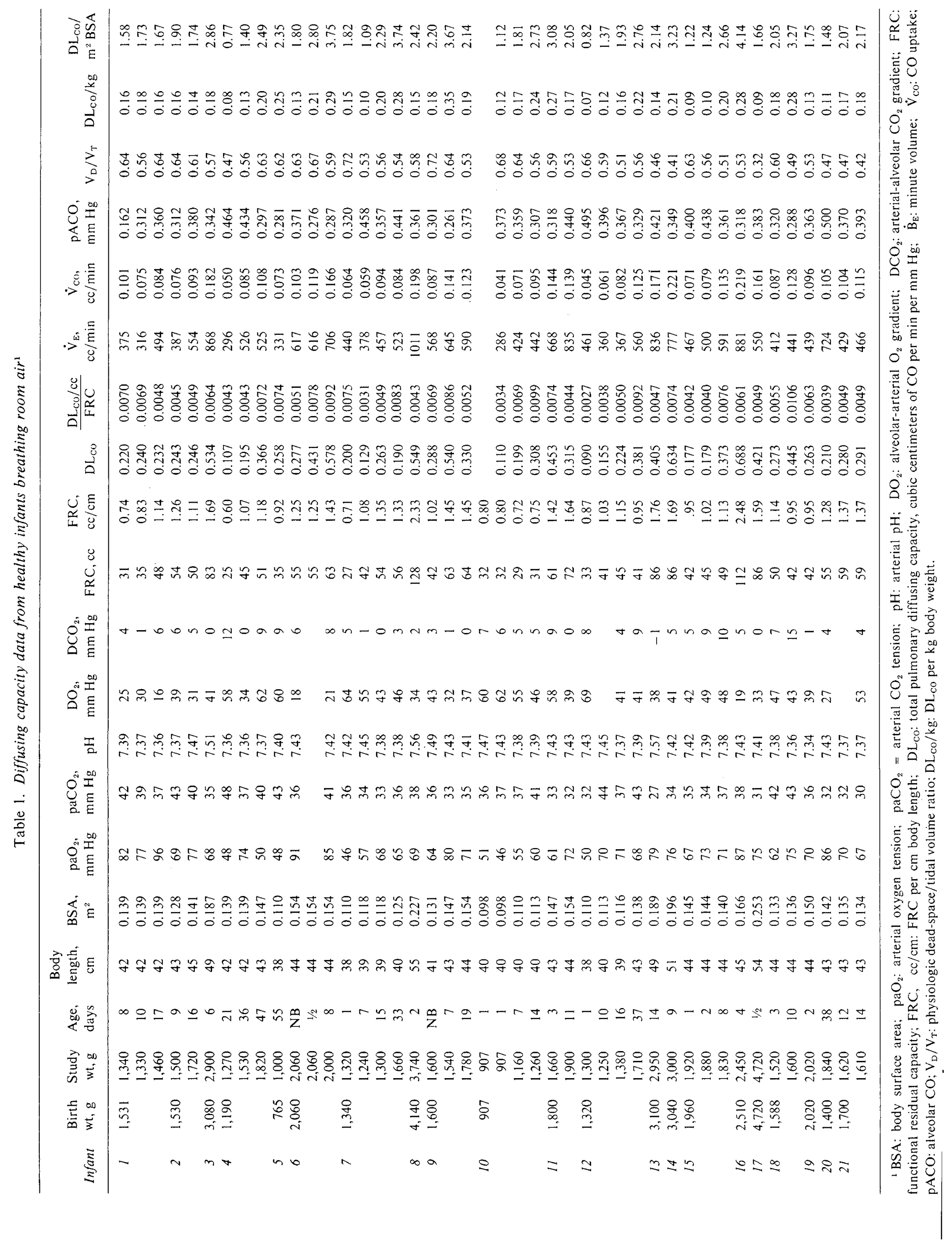



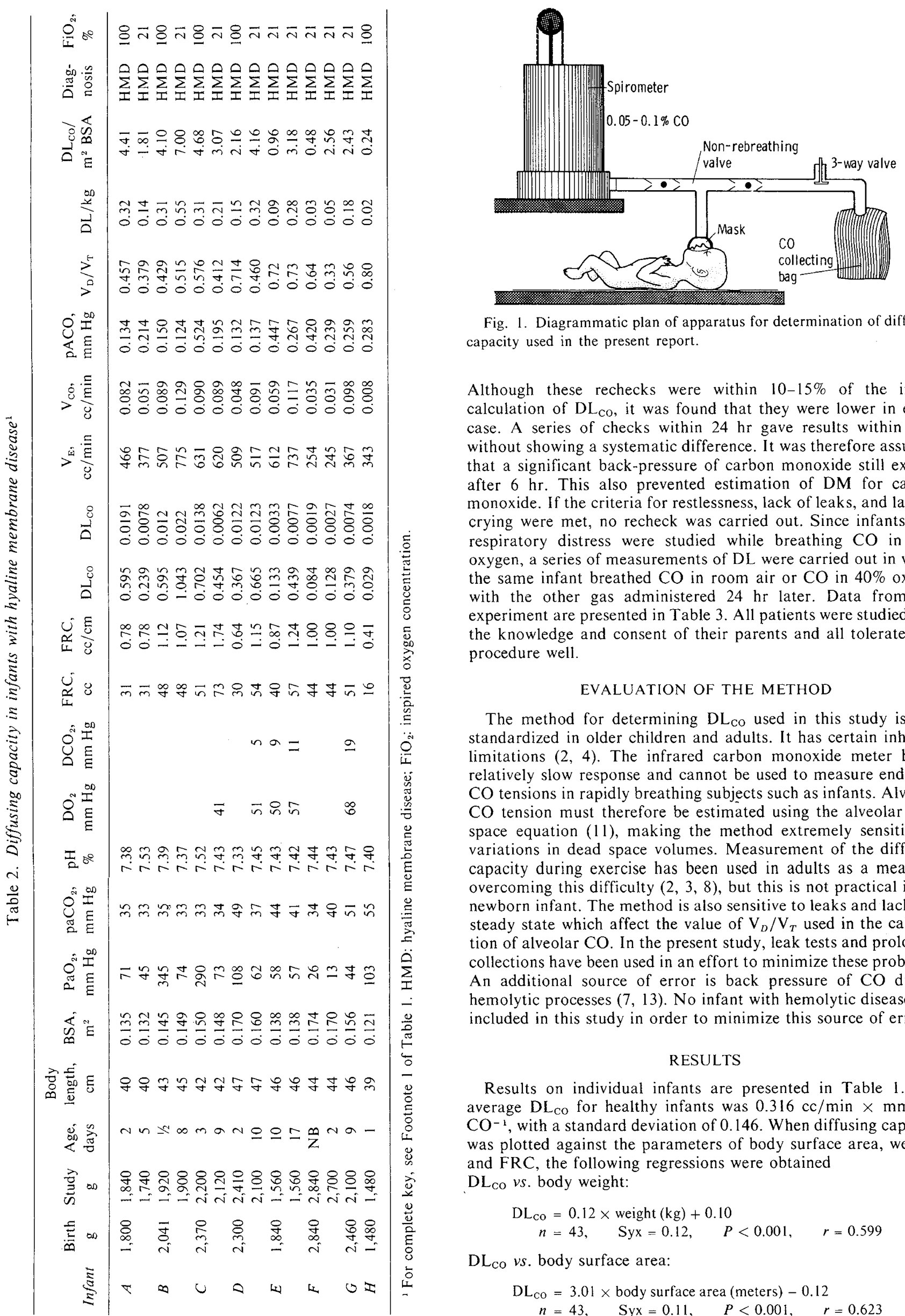

Fig. 1. Diagrammatic plan of apparatus for determination of diffusing capacity used in the present report.

Although these rechecks were within $10-15 \%$ of the initial calculation of $\mathrm{DL}_{\mathrm{CO}}$, it was found that they were lower in every case. A series of checks within $24 \mathrm{hr}$ gave results within $15 \%$ without showing a systematic difference. It was therefore assumed that a significant back-pressure of carbon monoxide still existed after $6 \mathrm{hr}$. This also prevented estimation of DM for carbon monoxide. If the criteria for restlessness, lack of leaks, and lack of crying were met, no recheck was carried out. Since infants with respiratory distress were studied while breathing $\mathrm{CO}$ in $40 \%$ oxygen, a series of measurements of DL were carried out in which the same infant breathed $\mathrm{CO}$ in room air or $\mathrm{CO}$ in $40 \%$ oxygen with the other gas administered $24 \mathrm{hr}$ later. Data from this experiment are presented in Table 3. All patients were studied with the knowledge and consent of their parents and all tolerated the procedure well.

\section{EVALUATION OF THE METHOD}

The method for determining $\mathrm{DL}_{\mathrm{Co}}$ used in this study is well standardized in older children and adults. It has certain inherent limitations $(2,4)$. The infrared carbon monoxide meter has a relatively slow response and cannot be used to measure end-tidal $\mathrm{CO}$ tensions in rapidly breathing subjects such as infants. Alveolar $\mathrm{CO}$ tension must therefore be estimated using the alveolar dead space equation (11), making the method extremely sensitive to variations in dead space volumes. Measurement of the diffusing capacity during exercise has been used in adults as a means of overcoming this difficulty $(2,3,8)$, but this is not practical in the newborn infant. The method is also sensitive to leaks and lack of a steady state which affect the value of $\mathrm{V}_{D} / \mathrm{V}_{T}$ used in the calculation of alveolar $\mathrm{CO}$. In the present study, leak tests and prolonged collections have been used in an effort to minimize these problems. An additional source of error is back pressure of $\mathrm{CO}$ due to hemolytic processes $(7,13)$. No infant with hemolytic disease was included in this study in order to minimize this source of error.

\section{RESULTS}

Results on individual infants are presented in Table 1. The average $D_{\text {Co }}$ for healthy infants was $0.316 \mathrm{cc} / \mathrm{min} \times \mathrm{mm} \mathrm{Hg}$ $\mathrm{CO}^{-1}$, with a standard deviation of 0.146 . When diffusing capacity was plotted against the parameters of body surface area, weight, and FRC, the following regressions were obtained

$\mathrm{DL}_{\mathrm{CO}} v s$. body weight:

$$
\begin{aligned}
\mathrm{DL}_{\mathrm{Co}} & =0.12 \times \text { weight }(\mathrm{kg})+0.10 \\
n & =43, \quad \text { Syx }=0.12, \quad P<0.001, \quad r=0.599
\end{aligned}
$$

$\mathrm{DL}_{\mathrm{co}} v s$. body surface area:

$$
\begin{aligned}
\mathrm{DL}_{\mathrm{CO}} & =3.01 \times \text { body surface area (meters) }-0.12 \\
n & =43, \quad \text { Syx }=0.11, \quad P<0.001, \quad r=0.623
\end{aligned}
$$


$\mathrm{DL}_{\mathrm{CO}} v s$. functional residual capacity:

$$
\begin{aligned}
\mathrm{DL}_{\mathrm{CO}} & =0.005 \times \mathrm{FRC}(\mathrm{cc})+0.043 \\
n & =43, \quad \text { Syx }=0.09, \quad P<0.001, \quad r=0.758
\end{aligned}
$$

The differences between these correlations coefficients are not statistically significant, using Student's $t$-test. Figure 2 represents the plot of diffusing capacity $v s$. lung volume for healthy infants and infants with hyaline membrane disease.

When $\mathrm{DL}_{\mathrm{Co}}$ was plotted against arterial oxygen tension while breathing room air, a weak positive correlation $(r=0.391, P<$ $0.01)$ was obtained. This is depicted in Figure 3. A similar negative correlation $(r=-0.391, P<0.02)$ was obtained by correlating $\mathrm{DL}_{\mathrm{Co}}$ with the alveolar-arterial oxygen difference.

Because of the high correlation between lung volume and $\mathrm{DL}_{\mathrm{CO}}$, an attempt to compare individuals of differing lung volumes was made by calculating the specific diffusing capacity, or $\mathrm{DL}_{\mathrm{co}} / \mathrm{cc}$ FRC of healthy infants was 0.0059 with a standard deviation of 0.0019 . Specific diffusing capacity showed no correlation with arterial oxygen tension in healthy infants $(r=0.06, P>0.9$; Fig. $4)$, or with alveolar-arterial oxygen gradient $(r=0.08, P>0.6)$.

No systematic statistically significant differences were found in paired studies of $\mathrm{DL}_{\mathrm{CO}}$ in room air or $40 \%$ oxygen (Table 2). The diffusing capacity measured in infants breathing $40 \%$ oxygen was $80 \%$ that measured under similar conditions while breathing room air. Normal values obtained for diffusion in room air were assumed to apply to data obtained while breathing CO in $40 \%$ oxygen. No adverse effects were observed during the short test period while $40 \% \mathrm{O}_{2}$ was inspired.

Significant correlations between FRC and arterial $\mathrm{pO}_{2}(r=$ $0.443, P<0.005)$ and alveolar-arterial oxygen gradient $(r=$ $-0.437, P<0.005$ ) were obtained.

Only the two most severely ill infants $(F$ and $H$ ) showed significant reductions in diffusing capacity during their illness. All others showed normal or slightly increased diffusing capacities. With the exception of infants $F$ and $H$, all distressed infants were well when restudied. During the recovery phase, all infants had normal diffusing capacities. Although both infants with hyaline membrane disease who had reduced diffusing capacities had arterial hypoxemia (infants $F$ and $H$ ), hypoxemia was also found in infants with normal diffusing capacities (infant $A$, day 2 ; infant $D$, day 2).

\section{DISCUSSION}

The present report establishes standards for diffusing capacity for carbon monoxide, determined by the steady state method, in low birth weight infants. The weak correlation between diffusing

Table 3. Diffusing capacity of carbon monoxide $\left(D L_{C O}\right)$ in room air vs. $40 \%$ oxygen ${ }^{1}$

\begin{tabular}{lcccc}
\hline \multicolumn{1}{c}{ Case } & $\begin{array}{c}\mathrm{DL}_{\mathrm{CO}} \\
\text { in room air }\end{array}$ & $\begin{array}{c}\mathrm{DL}_{\mathrm{CO}} / \mathrm{FRC}^{2} \\
\text { in room air }\end{array}$ & $\begin{array}{c}\mathrm{DL}_{\mathrm{CO}} \\
\text { in } 40 \% \mathrm{O}_{2}\end{array}$ & $\begin{array}{c}\mathrm{DL}_{\mathrm{CO}} / \mathrm{FRC} \\
\text { in } 40 \% \mathrm{O}_{2}\end{array}$ \\
\hline 12 & 0.381 & 0.0092 & 0.251 & 0.0061 \\
16 & 0.688 & 0.0061 & 0.368 & 0.0033 \\
$18(1)$ & 0.273 & 0.0055 & 0.175 & 0.0035 \\
21 & 0.280 & 0.0048 & 0.415 & 0.0070 \\
20 & 0.210 & 0.0039 & 0.287 & 0.0052 \\
$I 8(2)$ & 0.445 & 0.0110 & 0.247 & 0.0060 \\
19 & 0.263 & 0.0063 & 0.285 & 0.0069 \\
Mean & 0.363 & 0.0067 & 0.290 & 0.0054 \\
$\quad 1 \mathrm{SD}$ & 0.164 & 0.0025 & 0.080 & 0.0015 \\
\hline
\end{tabular}

${ }^{1}$ Unpaired data: $\mathrm{DL}_{\mathrm{CO}}$ air vs. $\mathrm{DL}_{\mathrm{CO}} 40 \% \mathrm{O}_{2}: t=1.0615, P>0.30$; $\mathrm{DL}_{\mathrm{CO}} / \mathrm{FRC}$ air vs. $40 \% \mathrm{O}_{2}: t=1.1313, P>0.25$. Paired data: $\mathrm{DL}_{\mathrm{Co}}$ air $v s$. $\mathrm{DL}_{\mathrm{CO}} 40 \% \mathrm{O}_{2}: t=1.2029, P>0.25 ; \mathrm{DL}_{\mathrm{CO}} / \mathrm{FRC}$ air vs. $40 \% \mathrm{O}_{2}: t=$ 1.2530, $P>0.25$.

${ }^{2}$ Functional residual capacity.

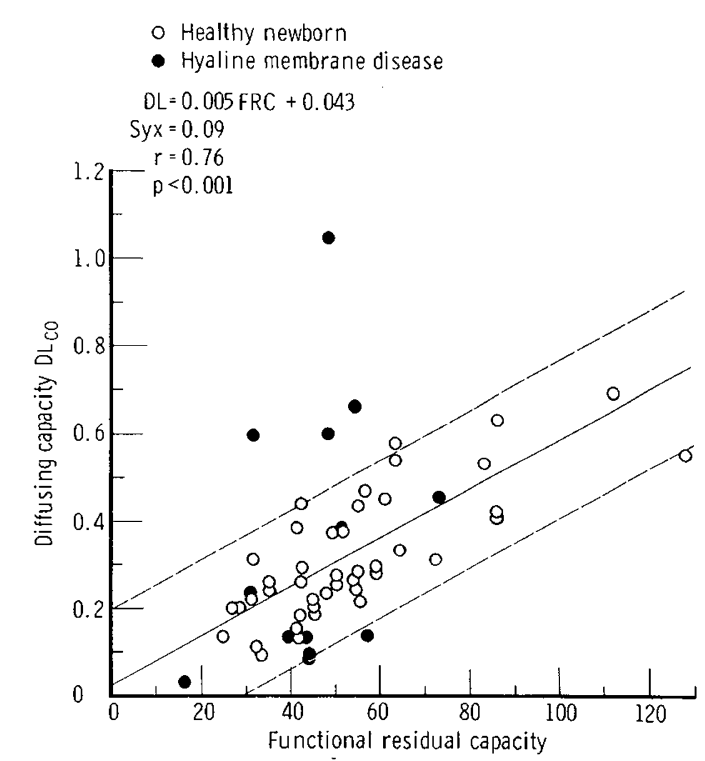

Fig. 2. Diffusing capacity for carbon monoxide $\left(D L_{c o}\right) v s$. functional residual capacity $(F R C)$ in cubic centimeters. $D L_{C O}$ units are cubic centimeters per min per $\mathrm{mm} \mathrm{Hg}$ of carbon monoxide.

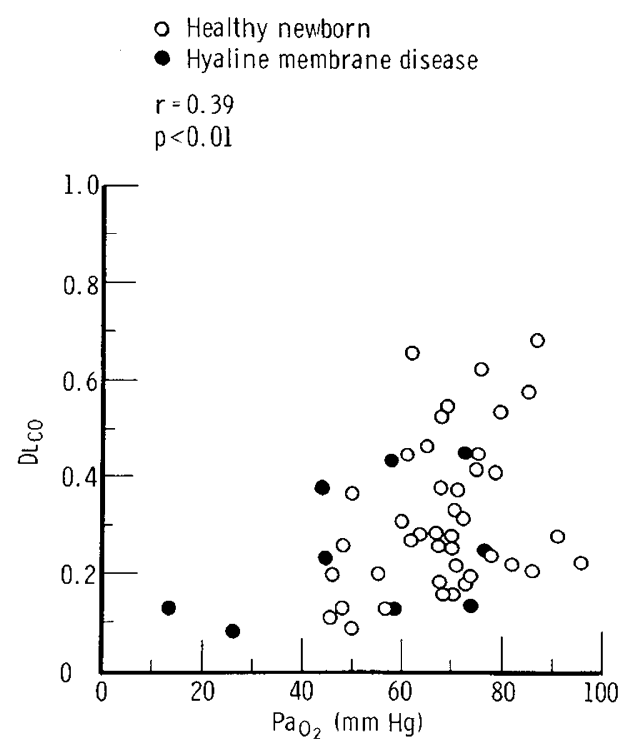

Fig. 3. Diffusing capacity for carbon monoxide $\left(D L_{C 0}\right)$ vs. arterial oxygen tension $\left(\mathrm{Pa}_{\mathrm{O}_{2}}\right)$ in $\mathrm{mm} \mathrm{Hg}$.

capacity and arterial oxygen tension is similar to that found in newborn infants by Nelson et al. (14) and Koch (10), and in adults with pulmonary disease by Finley and colleagues (9). This suggests that diffusing capacity is not a major determinant of arterial oxygen tension in the resting individual. The strong correlation observed between the observed diffusing capacity and functional residual capacity is similar to that observed by Bates and colleagues in exercising adults (3). Since diffusing capacity for carbon monoxide is dependent on many factors, including pulmonary capillary blood volume and the area of alveolar membrane available for diffusion, such a correlation is not unexpected.

Previous studies of diffusion in newborn infants at term by Nelson (14), Koch (10), and Stahlman (15) have shown diffusing capacities in the range of $1-3 \mathrm{cc} / \mathrm{min} \times \mathrm{mm} \mathrm{Hg} \mathrm{CO}^{-1}$. Adults studied in the pulmonary function laboratory of The New York Hospital have diffusing capacity of $0.006 \mathrm{cc} \mathrm{CO} / \mathrm{min} / \mathrm{mm} \mathrm{Hg}$ / cc FRC. This is close to the mean value for specific diffusing capacity of low birth weight infants obtained in the present study, and suggests that a major factor accounting for the 
reduced diffusing capacity of newborn infants is their reduced lung volume, and the associated loss of alveolar area and pulmonary blood volume.

The mean values for carbon monoxide diffusing capacity in newborn infants of varying weights and gestational ages obtained from previous studies in the literature are listed in Table 4 along with values obtained for healthy adults at rest $(2,3,8)$. The mean value obtained in the present study is somewhat lower than those of others, and the coefficient of variation somewhat higher, although it compares favorably with that of Stahlman (15). These differences are more marked for smaller infants than larger infants in the present study, the larger infants falling just outside the lower limits of the others $(10,15)$. Physiologic rather than methodologic differences account for this. The greater dispersion of the infants in the present study when compared with either term infants in other studies or adults may be in part attributed to the greater difficulty

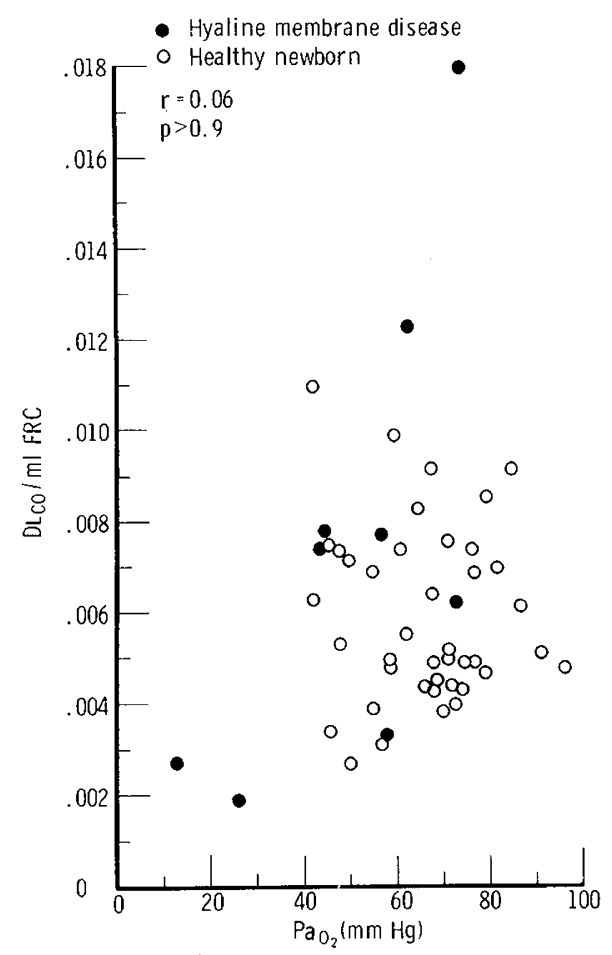

Fig. 4. Specific diffusing capacity for carbon monoxide $\left(D L_{c o}\right.$ per $\mathrm{cc}$ functional residual capacity $(F R C) v s$. arterial oxygen tension in $\mathrm{mm} \mathrm{Hg}$.

Table 4. Comparison of diffusing capacities of carbon monoxide $\left(D L_{C O}\right)$ in adults and children

\begin{tabular}{|c|c|c|c|c|c|}
\hline Reference & Subjects & $\begin{array}{l}\text { No. of } \\
\text { obser- } \\
\text { vations }\end{array}$ & $\begin{array}{c}\mathrm{DL}_{\mathrm{co}}, \mathrm{cc} / \\
\mathrm{min} \times \mathrm{mm} \\
\mathrm{Hg}^{-1}\end{array}$ & $\mathrm{SD}$ & $\begin{array}{c}\text { Coeffi- } \\
\text { cient } \\
\text { of } \\
\text { varia- } \\
\text { tion, } \\
\%^{1}\end{array}$ \\
\hline This paper & $\begin{array}{l}\text { Low birth wt } \\
\text { infants }\end{array}$ & 43 & 0.316 & 0.146 & 46 \\
\hline Stahlman (13) & $\begin{array}{l}\text { Full term } \\
\text { infants }\end{array}$ & 31 & 1.56 & 0.61 & 39 \\
\hline Koch (9) & $\begin{array}{l}\text { Full term infants, } \\
0-24 \mathrm{hr} \text { old }\end{array}$ & 26 & 2.2 & 0.5 & 23 \\
\hline Koch (9) & $\begin{array}{l}\text { Full term infants, } \\
7 \text { days old }\end{array}$ & 29 & 2.0 & 0.5 & 25 \\
\hline Bates et al. (3) & $\begin{array}{l}\text { Healthy adults at } \\
\text { rest }\end{array}$ & 18 & 17.6 & 5.0 & 28 \\
\hline
\end{tabular}

\footnotetext{
${ }^{1}$ Coefficient of variation $=\mathrm{SD} /$ mean $\times 100$.
}

in attaining a "steady state" in these very small infants. The lower values for diffusing capacity in the premature infants may be attributed to the fact that the lungs of these infants are somewhat underperfused, as indicated by their elevated dead space to tidal volume ratios $(11,18)$ and the presence of arterial-alveolar differences for carbon dioxide $(10,16)$, as well as the fact that low birth weight infants also have lower lung volumes for their size than heavier, more mature infants $(12,18)$. Both pulmonary underperfusion, by a reduction in the pulmonary capillary blood volume, as well as reduced lung volumes, are important determinants of the pulmonary diffusing capacity for carbon monoxide (5). In addition, the back pressure of $\mathrm{CO}$ due to hemolysis may be significant in small sick infants, and this is an additional source of possible error resulting in a low $\operatorname{DL}_{C O}(7,13)$. The wide variations in these factors which account for the relatively large range of values encountered in nondistressed low birth weight infants may also account for the great scatter of diffusing capacities measured in the eight infants with hyaline membrane disease included in this study. Loss of lung volume and pulmonary underperfusion are major factors in this illness $(12,18)$. The present study does not provide information relative to the membrane component of diffusion, and so cannot settle the question of the role of the "hyaline membrane" found in respiratory distress.

\section{SUMMARY}

Steady state diffusing capacity for carbon monoxide was measured in 21 infants without respiratory distress and in 8 infants with clinical hyaline membrane disease. The average diffusing capacity for infants without respiratory disease was $0.316 \mathrm{cc} / \mathrm{min}$ $\times \mathrm{mm} \mathrm{Hg} \mathrm{CO}{ }^{-1}$. A high positive correlation was found between $\mathrm{DL}_{c o}$ and functional residual capacity $(r=0.758, P<0.001)$, and a weaker negative correlation between $\mathrm{DL}_{\text {co }}$ and arterial oxygen tension $(r=-0.391, P<0.02)$. These data suggest that lung volume, which represents the area available for diffusion, is a major determinant of diffusing capacity in the newborn infant, but that diffusion is only a weak component in determining the arterial oxygen tension of the neonate.

\section{REFERENCES AND NOTES}

1. Adamson, T. M., Hawkes, J. M., Reynolds, E. O. R., and Shaw, J. L.: Hypoxemia during recovery from severe hyaline membrane disease. Pediatrics, 44: 168 (1969).

2. Bates, D. V.: The uptake of carbon monoxide in health and in emphysema. Clin. Sci., 11: 21 (1952).

3. Bates, D. V., Boucot, N. G., and Dormer, A. E.: The pulmonary diffusing capacity in normal subjects. J. Physiol. (London), 129: 237 (1955).

4. Bates, D. V.. Macklem, P. T., and Christie, R. V.: Respiratory Function in Disease, Ed. 2, pp. 75-92 (W. B. Saunders, Philadelphia, 1971).

5. Briscoe, W. A., and King, T. K. C.: Analysis of the disturbance in oxygen transfer in hypoxic lung disease. Amer. J. Med., 57: 349 (1974).

6. Comroe, J. H., Forster, R. E., Dubois, A. B., Briscoe, W. A., and Carlsen, E.: The Lung, pp. 184-186 (Year Book Medical Publishers, Chicago, 1955).

7. Fallstrom, S. P.: On the endogenous formation of carbon monoxide in full-term newborn infants. Acta Paediat. Scand., (Suppl. 189): 1 (1968).

8. Filley, G. F., MacIntosh, D. J., and Wright, G. W.: Carbon monoxide uptake and pulmonary diffusing capacity in normal subjects at rest and during exercise. $J$. Clin. Invest., 33: 530 (1954).

9. Finley, T. N., Swenson, E. W., and Comroe, J. H.: The cause of arterial hypoxemia at rest in patients with "alveolar-capillary block syndrome." J. Clin. Invest., $41: 618$ (1962).

10. Koch, G.: Alveolar ventilation, diffusing capacity and the $\mathrm{A}-\mathrm{a} \mathrm{Po}_{2}$ difference in the newborn infant. Resp. Physiol., 4: 168 (1968).

11. Krauss, A. N. and Auld, P. A. M.: Ventilation-perfusion abnormalities in the premature infant: Triple gradient. Pediat. Res., 3: 255 (1969).

12. Krauss, A. N., and Auld, P. A. M.: Measurement of function residual capacity in distressed neonates by helium rebreathing. J. Pediat., 77: 228 (1970).

13. Maisels, M. J., Pathak, A., Nelson, N. M., Nathan, D. G., and Smith, G. A. Endogenous production of carbon monoxide and erythroblastotic infants. J. Clin. Invest., 50: I (1971).

14. Nelson, N. M., Smith, C. A., Cherry, R. B., and Riegel, K.: Der diffusion faktor und das effektive capillarblut-volumen der lunge beim idiopathischen atemnotsyndrom des neugebornen. Mschr. Kinderheilk., 115: 224 (1967).

15. Stahlman, M. T.: Pulmonary ventilation and diffusion in the human newborn infant. J. Clin. Invest., 36: 1018 (1957).

16. Thibeault, D. W., Clutario, B., and Auld, P. A. M.: Arterial oxygen tension 
tension in premature infants. J. Pediat., 69: 449 (1966).

17. Thibeault, D. W., Poblete, E., and Auld, P. A. M.: Arteriat-alveolar oxygen difference in premature infants breathing 100\% oxygen. J. Pediat., 71: 814 (1967).

18. Tori, C. A., Krauss, A. N., and Auld, P. A. M.: Serial studies of lung volume and VA/Q in hyaline membrane disease. Pediat. Res., 7: 82 (1973).

19. Dr. A. N. Krauss has a fellowship with the Tuberculosis and Respiratory Disease

Copyright (C) 1976 International Pediatric Research Foundation, Inc.
Association of New York

20. Dr. P. A. M. Auld was supported by United States Public Health Service Research Grant HD-02644.

21. Requests for reprints should be addressed to: P. A. M. Auld, M.D., Division of Newborn Medicine, Department of Pediatrics, New York Hospital Cornell University Medical Center, 522 E. 68th St., New York, N.Y. 10021 (USA). 22. Accepted for publication March 3,1976.

\title{
Skin Reflectance in the Newborn Infant
}

\author{
ALFRED N. KRAUSS, ${ }^{\prime 10}$ PETER W. POST, STEPHANIE WALDMAN, AND PETER A. M. AULD \\ Department of Pediatrics, Division of Perinatology. The New York Hospital-Cornell Medical Center, New York, \\ New York, and Department of Anthropology, The Ohio State University, Columbus, Ohio, USA
}

\section{Extract}

Skin reflectance in red, green, and blue light was measured at the sternum of 99 Caucasian infants ranging in gestational age from 26 to 44 weeks. Skin reflectance was consistently higher in female infants, but this difference was not statistically significant. Highly significant $(P<\mathbf{0 . 0 0 1})$ increases in reflectance at all wave lengths were found when sternal reflectance during the first $\mathbf{4 8} \mathrm{hr}$ of life was related to gestational age. The dispersion of data points about the regression line does not permit this method to be relied upon as the sole means of determining gestational age of infants. Serial studies indicate that reflectance increases in premature infants not given phototherapy, whereas premature infants receiving phototherapy show a fall in reflectance for the duration of therapy. This suggests that phototherapy may cause tanning of the skin.

\section{Speculation}

Reflectance spectrometry provides a safe, noninvasive method to assess human newborn skin maturation and may also be a means to determine effects of various therapeutic regimens on the skin.

The most commonly used system for assessing gestational age of newborn infants is that of Dubowitz and colleagues (3). Many of the items contained in the Dubowitz scale require a subjective evaluation of a particular characteristic on the part of the examiner. Evaluation of the skin for color, thickness, and opacity is required to complete this scale and determine the infant's score. Reflectance spectrophotometry is a safe, noninvasive method for assessing the physical characteristics of the skin and has been widely used and standardized in adults (6). Reflectance of light by the skin depends on the wave length of light used, the skin thickness, and the amount of pigment in the skin. In adults these factors are also influenced by the sex and site of sampling in an individual subject because of variations in the amount of pigment because of sex, relation to pubertal status, and tanning. The aim of the present study was to determine whether measurements of skin reflectance in newborn infants could be standardized to provide a measurement of gestational age and give an objective verification of Dubowitz' data.

\section{METHODS}

Forty-seven male and fifty-two female Caucasian infants were included in this study. Racial identification was voluntarily provided by the parents for birth certificates. All infants were healthy at the time of study and none had received phototherapy before the study. All infants had parents who lived within a 70-mile radius of New York City. The infants ranged in gestational age from 25 to 44 weeks, based on information obtained from the date of the mother's last menstrual period. Additionally, all infants were examined by one of the investigators in order to determine gestational age by means of the Dubowitz criteria (3). If the discrepancy between the mother's dates and physical examination exceeded 2 weeks the infant was excluded from the study. All infants were studied with their parents' knowledge and informed consent according to a protocol approved by the New York Hospital Human Rights Committee.

Infants born after 36 weeks of gestation were studied only once within $48 \mathrm{hr}$ of birth. Premature infants were studied initially within $48 \mathrm{hr}$ of birth and again at 3-day intervals until 1 week of age, and then at weekly intervals until discharge. No mature infant who received phototherapy is included in this study. Some premature infants did receive phototherapy for hyperbilirubinemia, and are so indicated in the appropriate figure. Standard statistical techniques (Student's $t$-test, least squares determination of regression coefficients) were used to compare data between various groups of infants.

Skin reflectance was measured with a model 670 Photovolt "reflection meter" (9). Light from a clear 6-W tungsten bulb is transmitted to the skin at a $0^{\circ}$ angle through various filters and monitored with a compensating photocell (9). Light reflected from the skin is measured by a second photocell at a $45^{\circ}$ angle to the incident beam. Bulb, filters, and photocells form a reflectance unit which is placed directly in contact with the skin. The reflectance unit is connected to a microammeter which records the current generated on a linear scale. The machine is standardized so that full scale current (100\% reflectance) corresponds to the reflection from a magnesium oxide standard tile. High reflectance corresponds to "whiter" skin. Filters used to transmit light were standard Corning glass filters: blue (CS5-60/5543), green (CS4-64/4010), and red (CS2-59/2404). These filters were 2.0, 3.0, and $4.0 \mathrm{~mm}$ thick, respectively. Measurements were made by one 